\title{
MicroRNA Profiling of Exosomes
}

\section{Melissa Daly and Lorraine 0'Driscoll}

\begin{abstract}
Exosomes are nano-sized membrane-bound vesicles released by a range of different cell types. Exosomes have been shown to specifically package certain membrane and cytosolic proteins and nucleic acids. Furthermore, it has been shown that their contents can be transferred to secondary cells, affecting the recipient cells' cellular processes. Exosomes are present in a multitude of body fluids and so represent a novel source of circulating biomarkers. Here, we describe ultracentrifugation methods suitable for the isolation of exosomes from serum and plasma. We also detail transmission electron microscopy, nanoparticle tracking analysis, and immunoblotting methods suitable for the characterization of exosomes.
\end{abstract}

Key words Exosomes, Serum, Plasma, Ultracentrifugation, Characterization

\section{Introduction}

Exosomes are nano-sized (30-120 nm), membrane-bound vesicles released by a range of different cell types. Exosomes are released when multi-vesicular bodies fuse with the cell membrane and expel their contents into the extracellular space [1]. Exosomes represent an exciting area of biomarker research, as their contents are a wealth of information on the state of their cell of origin and they are present in a multitude of body fluids, including blood, semen, and saliva; to name but a few [2]. Exosomes are also thought to be important mediators in intercellular communication. Indeed, many studies have found evidence that their contents, including membrane and cytosolic proteins, DNA and various types of RNA, can be transferred to cells either through membrane-membrane interaction or direct uptake of the exosome and that they can directly influence the cellular processes of the recipient cell [3-5]. Exosomes appear particularly relevant to the area of microRNA (miRNA) research as, not only have they been shown to be enriched in miRNA, their lipid membrane structure acts as a protective barrier from RNase degradation. Studies have identified exosomal miRNAs as potential diagnostic and prognostic biomarkers in many 
cancers including lung [6], brain [7], breast [8], ovarian $[9,10]$, and prostate cancer [11].

The success of such studies is dependent on good exosome isolation and characterization techniques. Herein we outline the use of ultracentrifugation, and a variation using a density gradient, for the isolation of exosomes from serum and plasma and the use of transmission electron microscopy (size and morphology), nanoparticle tracking analysis (size and concentration), and immunoblots (presence of exosome markers) as standard methods for exosome characterization [12].

\section{Materials}

\subsection{Serum Collection}

\subsection{Ultra-} centrifugation
1. Non-heparinized tube(s) for blood collection (by trained Phlebotomist).

2. Bench-top centrifuge.

3. Cryovial tubes.

4. $-80{ }^{\circ} \mathrm{C}$ freezer.

1. Ultracentrifuge and appropriate fixed-angle or swinging bucket rotor (for details on Beckman Coulter ultracentrifuge rotors and accessories see: http://www.labplan.ie/admin/documents/Ultracentrifuge_Rotors_Tubes_Accs_06.pdf).

2. Polyallomer or polycarbonate centrifuge tubes appropriate for rotors mentioned in Item $\mathbf{1}$.

3. Phosphate-buffered saline (PBS): sodium chloride $8 \mathrm{~g} / \mathrm{L}$, potassium chloride $0.2 \mathrm{~g} / \mathrm{L}$, di-sodium hydrogen phosphate $1.15 \mathrm{~g} / \mathrm{L}$, and potassium dihydrogen phosphate $0.2 \mathrm{~g} / \mathrm{L}$ $\mathrm{pH} 7.3$ at $25^{\circ} \mathrm{C}$.

4. $0.22 \mu \mathrm{m}$ low protein binding syringe filters.

5. $10 \mathrm{~mL}$ Syringes.

6. 18-G syringe needles.

7. $30 \mathrm{~mL}$ universal tubes. For the Optiprep density gradient variation

8. Optiprep density gradient medium $(60 \% \mathrm{w} / \mathrm{v})$ (Sigma-Aldrich).

9. Dilution buffer: $0.25 \mathrm{M}$ sucrose, $1 \mathrm{mM}$ EDTA and $10 \mathrm{mM}$ Tris-HCl, $\mathrm{pH}$ 7.4. (There are a number of similar dilution buffers for this type of gradient. For details please see: http:// www.axis-shield-density-gradient-media.com/Preparation $\% 20$ of $\% 20$ gradient $\% 20$ solutions.pdf).

1. Transmission electron microscope (TEM).

2. Formvar/carbon-coated nickel or copper grids.
2.3 Transmission Electron Microscopy 
3. PBS: sodium chloride $8 \mathrm{~g} / \mathrm{L}$, potassium chloride $0.2 \mathrm{~g} / \mathrm{L}$, disodium hydrogen phosphate $1.15 \mathrm{~g} / \mathrm{L}$, and potassium dihydrogen phosphate $0.2 \mathrm{~g} / \mathrm{L} \mathrm{pH} 7.3$ at $25{ }^{\circ} \mathrm{C}$.

4. $4 \%$ glutaraldehyde: Dilute glutaraldehyde in $0.1 \mathrm{M}$ sodium phosphate buffer, $\mathrm{pH} 7.4$, to a final concentration of $4 \%$.

5. $2 \%$ uranyl acetate, $\mathrm{pH}$ 4.0: Dissolve $\mathrm{l} \mathrm{g}$ in $50 \mathrm{~mL}$ distilled $\mathrm{H}_{2} \mathrm{O}$. This may be stored at $4{ }^{\circ} \mathrm{C}$ in the dark for up to 6 months. Prior to use, filter required volume through a $0.22 \mu \mathrm{m}$ filter.

6. Parafilm.

7. Whatman no. 1 filter paper.

8. Forceps.

2.4 Nanoparticle Tracking Analysis

2.5 SDSPolyacrylamide Electrophoresis

\subsection{Immunoblotting}

1. NanoSight NS300 (or NS500).

2. $100 \mathrm{~nm}$ polystyrene latex calibration nanoparticles.

3. PBS.

4. $1 \mathrm{~mL}$ syringes.

1. Resolving buffer $(4 \times)$ : $1.5 \mathrm{M}$ Tris- $\mathrm{HCl}, \mathrm{pH} 8.8,0.4 \%$ SDS. Stored at room temperature.

2. Stacking buffer $(4 \times)$ : $0.5 \mathrm{M}$ Tris- $\mathrm{HCl}, \mathrm{pH} \quad 6.8,0.4 \%$ SDS. Stored at room temperature.

3. Sample buffer $(4 \times): 4 \mathrm{~mL}$ stacking buffer, $2 \mathrm{~mL} \beta$-mercaptoethanol, $6 \mathrm{~mL}$ glycerol, $1 \mathrm{~g}$ SDS and $50 \mathrm{mg}$ bromophenol blue. Aliquot and store at $-20{ }^{\circ} \mathrm{C}$.

4. Acrylamide/bis-acrylamide, $30 \%$ solution (Sigma-Aldrich). Stored at $4{ }^{\circ} \mathrm{C}$.

5. $N, N, N, N^{\prime}$-Tetramethyl-ethylenediamine (TEMED).

6. Ammonium persulfate: $10 \%$ solution in distilled water, freshly prepared.

7. Running buffer (10×): $25 \mathrm{mM}$ Tris $\mathrm{pH} 8.3,192 \mathrm{mM}$ glycine, and $0.1 \%$ SDS. Stored at room temperature.

8. Prestained molecular weight markers: SeeBlue ${ }^{\circledR P l u s 2}$ Prestained protein standard (Bio-Sciences, Ireland).

9. 1-D Electrophoresis system (ATTO Corporation, Tokyo, Japan).

1. Blotting buffer: buffer $(10 \times): 25 \mathrm{mM}$ Tris $\mathrm{pH} 8.3,192 \mathrm{mM}$ glycine, and $20 \%(\mathrm{v} / \mathrm{v})$ methanol. Stored at $4{ }^{\circ} \mathrm{C}$.

2. Immun-Blot PVDF membrane and extra thick blot paper.

3. Ponceau $S$ solution.

4. Phosphate buffered saline (PBS, $1 \times$ ): $0.01 \mathrm{M}$ phosphate buffer, $0.0027 \mathrm{M}$ potassium chloride and $0.137 \mathrm{M}$ sodium chloride, $\mathrm{pH} 7.4$. 
5. Washing buffer (PBS-T): $1 \times$ PBS supplemented with $0.1 \%$ Tween-20.

6. Blocking buffer: $5 \%(\mathrm{w} / \mathrm{v})$ bovine serum albumin (BSA) solution in PBST.

7. Antibody dilution buffer: $1 \times$ PBS supplemented with $3 \%$ $(\mathrm{w} / \mathrm{v})$ BSA and $0.1 \%$ Tween-20. Aliquots frozen at $-20^{\circ} \mathrm{C}$.

8. Primary antibodies: rabbit anti-Grp94 antibody (Cell Signalling Technology Europe, The Netherlands) diluted 1:1000 in antibody dilution buffer, mouse anti-TSG101 antibody (Abcam, Cambridge, UK) diluted 1:1000 in antibody dilution buffer and rabbit anti-CD81 (Santa Cruz Biotechnology Inc., CA) diluted 1:200 in antibody dilution buffer.

9. Secondary antibodies: Anti-rabbit and anti-mouse IgG HRPconjugated (Cell Signalling) diluted 1:1000 in antibody dilution buffer.

10. Enhanced chemiluminescent reagent: SuperSignal West Pico Chemiluminescent Substrate (ThermoFischer Scientific).

11. Stripping buffer: $62.5 \mathrm{mM}$ Tris- $\mathrm{HCl}, \mathrm{pH} 6.8,2 \%(\mathrm{w} / \mathrm{v})$ SDS. Before usewarm to $70^{\circ} \mathrm{Candadd} 100 \mathrm{mM} \beta$-mercaptoethanol.

12. Semi-dry transfer system (BioRad Laboratories Inc.).

13. Imaging system: ChemiDoc XRS system (BioRad Laboratories Inc.).

\section{Methods}

\subsection{Serum Collection}

3.2 Ultracentrifugation
1. Allow blood in non-heparinized tube(s) to clot for $30 \mathrm{~min}$ minimum to $\mathrm{l} \mathrm{h}$ maximum.

2. Centrifuge at $1000 \times g$ for $10 \mathrm{~min}$ at room temperature.

3 . Gently remove the serum and aliquot into labeled cryovial tubes.

4. Store at $-80^{\circ} \mathrm{C}$ within $<3 \mathrm{~h}$ of procurement.

The most commonly used and preferred method by which exosomes are isolated from serum or plasma is ultracentrifugation. The procedure outlined here is an adaptation of a technique previously described for conditioned media and bodily fluids [13].

1. Dilute a known volume (see Note 1 ) of serum or plasma to $5 \mathrm{~mL}$ in PBS.

2. Filter this suspension through a $0.22 \mu \mathrm{m}$ syringe filter.

3 . Using a fresh syringe place the filtrate in an ultracentrifuge tube. Using a waterproof marker place a mark on the bottom/ side of the tube where the pellet will be found following cen- 
3.2.1 Ultracentrifugation with Optiprep Density Gradient

\subsection{Transmission Electron Microscopy}

trifugation. For swinging bucket rotors the pellet will be found at the bottom and for fixed angle rotors the pellet will be found on the side facing out.

4. Fill the ultracentrifuge tube with $\mathrm{PBS}$ and centrifuge at $110,000 \times g$ for $75 \mathrm{~min}$ at $4{ }^{\circ} \mathrm{C}$.

5 . Remove the supernatant and carefully resuspend the exosome pellet in $1 \mathrm{~mL}$ PBS ( see Note 2).

6. Place the resuspended exosome pellet into a fresh centrifuge tube and fill with PBS.

7. Centrifuge at $110,000 \times \mathrm{g}$ for $75 \mathrm{~min}$ at $4{ }^{\circ} \mathrm{C}$.

8. Carefully remove the supernatant. Resuspend exosome pellet in $200 \mu \mathrm{L} \mathrm{PBS}$ and store at $-80^{\circ} \mathrm{C}$.

The procedure outlined above is considered adequate for exosomes isolation. If, after characterization, the exosomes are not of acceptable purity or yield is deemed insufficient for preferred profiling methods, the addition of a density gradient using a medium such as iodixanol is recommended.

1. Prepare 40,20, 10, and 5\% solutions of Optiprep density gradient medium using dilution buffer $(0.25 \mathrm{M}$ sucrose, $1 \mathrm{mM}$ EDTA, and $10 \mathrm{mM}$ Tris- $\mathrm{HCl}, \mathrm{pH} 7.4)$.

2. Using a syringe, carefully layer the gradient in an ultracentrifuge tube with equal volumes of 40,20 , and $10 \%$ solutions and $0.5 \mathrm{~mL}$ less of the $5 \%$ solution.

3 . Filter a known volume of serum (or plasma) through a 0.22 $\mu \mathrm{M}$ filter and place on top of the gradient.

4. Centrifuge at $100,000 \times g$ for $18 \mathrm{~h}$ at $4{ }^{\circ} \mathrm{C}$.

5 . Collect $1 \mathrm{~mL}$ fractions starting from the top of the gradient.

6. Centrifuge individual fractions at $100,000 \times g$ for $3 \mathrm{~h}$ at $4{ }^{\circ} \mathrm{C}$.

7. Resuspend exosome pellets in $100 \mu \mathrm{L}$ PBS.

8. Assess fractions for the presence of exosomes and if necessary pool exosome positive fractions before proceeding to miRNA profiling.

The procedure outlined here is an adaptation of a previously described technique sufficient for transmission electron microscopy (TEM) analysis of exosome preparations [14]

1. Place a drop $(\sim 30 \mu \mathrm{L})$ of intact EVs on parafilm.

2. Using a forceps gently place a formvar/carbon-coated grid, coated side down, on top of the drop. Leave for 30-60 min (see Note 3).

3. Place three drops, $>30 \mu \mathrm{L}$ each, of PBS on parafilm and wash the grid by placing the grid on top of each droplet for $5 \mathrm{~min}$ 


\subsection{Nanoparticle Tracking Analysis}

each using absorbent paper in between (see Note 3). Fix the sample by placing the grid on a drop of $4 \%$ glutaraldehyde for $10 \mathrm{~min}$.

4. Repeat wash as step 3.

5. Contrast the sample by placing a drop of $2 \%$ uranyl acetate onto parafilm and placing the grid on top of the drop for $15 \mathrm{~min}$.

6. Remove excess liquid using absorbent paper and allow the grids to air dry.

7. Once dry, grids can be examined by TEM immediately or can be stored in a suitable grid box for up to 2 weeks.

Nanoparticle tracking analysis uses light scattering and Brownian motion to measure the size and concentration of particles in solution. A laser light is used to illuminate particles and a series of videos are taken. The software analyses the videos tracking individual particles to assess their size and give the overall concentration of particles in the solution (Fig. 1).

1. Calibrate the system with $100 \mathrm{~nm}$ polystyrene latex calibration nanoparticles.

2. Dilute EV sample $1 / 10$ to $1 / 100$ in filtered PBS. It is advisable to analyze the PBS used to verify that it is particle free.

3. Place the sample in instrument. If using the NanoSight NS300 system the sample is manually placed inside the sample chamber using a $1 \mathrm{~mL}$ syringe. If using the NanoSight NS500 system place the sample tube on the platform and insert the inlet tube. The sample will be automatically pumped into the sample chamber during analysis.

4. Set temperature to $23^{\circ} \mathrm{C}$.

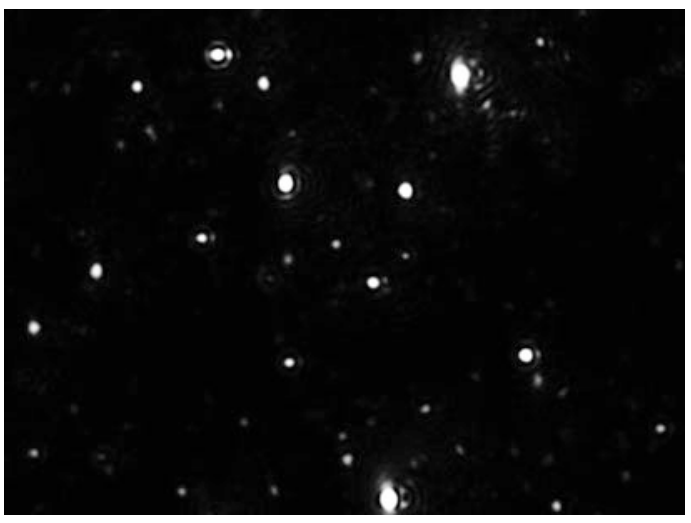

Fig. 1 Screenshot of video from Nanosight analysis of exosomes, isolated using ultracentrifugation, showing a suitable number (between 20 and 100) of particles per frame 
5. Start camera and adjust camera level to 15 . Samples should be clearly visible

6. Capture $560 \mathrm{~s}$ videos using a $30 \mathrm{~s}$ delay to make sure movement of particles can only be attributed to Brownian motion. If using the NanoSight NS300 system you will be prompted to manually pass the solution through the chamber between each video.

\subsection{SDS-PAGE}

\subsection{Immunoblotting}

1. The protocol here refers to the use of a mini gel 1-D gel electrophoresis system (ATTO Corporation) but can be adapted to other formats.

2. Clean the glass plates thoroughly with $70 \%(\mathrm{v} / \mathrm{v})$ ethanol and assemble the front and back plates in the clamps. Ensure there is no leakage by pouring water inside the plates and leaving for at least $5 \mathrm{~min}$. Remove the water.

3. Prepare a $10 \%$ gel solution using $2 \mathrm{~mL}$ of resolving buffer $(4 \times), 2.5 \mathrm{~mL}$ of $30 \%$ acrylamide/bis-acrylamide solution, $75 \mu \mathrm{L}$ of $10 \%$ SDS and $3 \mathrm{~mL}$ water. Add $40 \mu \mathrm{L}$ of ammonium persulfate and $3 \mu \mathrm{L}$ of TEMED. Mix and immediately pour the gel, taking care to leave enough room for the stacking gel. Slowly pour a small amount of distilled water (or ethanol) on top of the gel.

4. Pour off the water (or ethanol). Prepare the stacking gel using $250 \mu \mathrm{L}$ of stacking buffer, $340 \mu \mathrm{L} 30 \%$ acrylamide/bisacrylamide solution, $20 \mu \mathrm{L}$ of $10 \%$ SDS, and $1.4 \mathrm{~mL}$ water. Add $20 \mu \mathrm{L}$ of ammonium persulfate and $2 \mu \mathrm{L}$ of TEMED. Pour the stacking gel solution and immediately insert the combs.

5. Remove the plates from the holder and assemble the gasket. Fill the gasket and the outer chamber with running buffer and remove the comb.

6. Load the samples and the molecular weight marker in the wells.

7. Assemble the unit and connect to the power source. Use constant voltage up to $80 \mathrm{mV}$ through the stacking gel and up to $100 \mathrm{mV}$ through the resolving gel. Once the bromophenol blue dye has run off the gel, turn off and disconnect the power supply.

It is recommended to assess isolated exosomes for the presence of at least two extracellular vesicle positive markers (e.g. TSG101, $42 \mathrm{kDa}$; CD81, $26 \mathrm{kDa}$ ) and one negative marker (e.g. Grp94, $96 \mathrm{kDa}$ ) (Fig. 2). At present there are no protein markers verified as specific to exosomes, only those associated with extracellular vesicles (exosomes and microvesicles).

1. The protocol here refers to a semi-dry transfer method using a Bio-Rad Trans-blot system.

2. Cut a sheet of PVDF paper to slightly larger than the gel size and soak in methanol for $1 \mathrm{~min}$ to activate the membrane. 
Once activated leave to soak in transfer buffer until needed. Soak two sheets of extra thick paper in transfer buffer.

3. Carefully remove the gel from the gel unit. Remove the stacking gel and soak the resolving gel in transfer buffer. Note the orientation of the gel.

4. Prepare the transfer cell placing a sheet of extra thick paper and placing the membrane on top. Place the gel on top of the membrane and cover with the second sheet of extra thick paper. Ensure there are no air bubbles between the gel and the membrane.

5. Place the lid on top and connect the unit to the power supply. Transfer at $20 \mathrm{mV}$ for $1 \mathrm{~h}$.

6. Disconnect the power supply and carefully remove the lid of the transfer unit. Remove the paper and gel and check that the corresponding markers from the prestained marker are visible on the membrane.

7. Incubate the membrane in Ponceau $S$ staining solution for $1 \mathrm{~min}$.

8. Wash the membrane in three washes of PBST, 5 min each, with vigorous shaking to remove the stain.

9. Incubate the membrane in blocking buffer for $\mathrm{l} \mathrm{h}$ at room temperature on a gently shaking $(\sim 30 \mathrm{rpm})$ rocker.

10. Wash the membrane in three washes of PBST, 5 min each, with vigorous shaking.

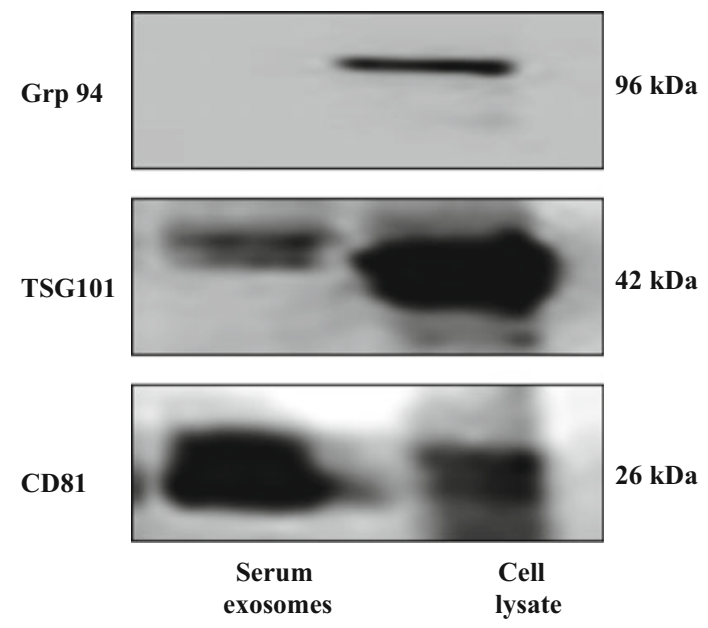

Fig. 2 Immunoblot analysis of samples of exosomes isolated from serum using ultracentrifugation for extracellular vesicle positive markers TSG101 and CD81 and negative marker GRP94. Cell lysate, here BT474, is typically used as a positive control for extracellular vesicle negative marker 
11. Incubate the membrane in primary antibody overnight at $4{ }^{\circ} \mathrm{C}$ with gentle shaking or at room temperature for $3 \mathrm{~h}$.

12. Remove the primary antibody ( see Note 4) and wash the membrane three times, $5 \mathrm{~min}$ each, in PBST with vigorous shaking.

13. Incubate the membrane in secondary antibody for $1 \mathrm{~h}$ at room temperature with gentle shaking.

14. Remove the secondary antibody (see Note 4) and wash the membrane three times, $5 \mathrm{~min}$ each, in PBST with vigorous shaking.

15. Place the blot in the tray of the imaging system. Mix the ECL reagents at a ratio of $1: 1$ and apply evenly to the blot for $3 \mathrm{~min}$. Proceed with imaging.

16. After a suitable signal has been obtained, wash the blot once more with PBST to remove any excess ECL solution. If necessary carry out the stripping procedure before probing for another extracellular vesicle marker.

17. For the stripping procedure, warm $30 \mathrm{~mL}$ of stripping buffer to $70{ }^{\circ} \mathrm{C}$ and then add $100 \mathrm{mM}$ of $\beta$-mercaptoethanol. Incubate the membrane in just enough buffer to cover it for $10 \mathrm{~min}$. Replace the buffer with fresh buffer for a further $10 \mathrm{~min}$. Wash the membrane twice, $10 \mathrm{~min}$ each, with PBS and once, $10 \mathrm{~min}$, with PBST. Repeat the blocking step before reprobing with primary antibody.

\section{Notes}

1. Use a minimum of $250 \mu \mathrm{L}$ of serum or plasma for exosomes isolation.

2. Exosomes are nano-sized and so the pellet produced may not be visible to the naked eye. For this reason, it is important to mark the tube prior to ultracentrifugation so as to be aware of where the pellet is placed.

3. During the washing and fixing steps ensure that the grid is not allowed to dry out while keeping the back of the grid dry. Remove excess solution by gently touching the circumference of the grid against a Whatman no.l filter paper.

4. Antibody dilutions can be used several times. Store antibody dilutions at $-20{ }^{\circ} \mathrm{C}$. 


\section{References}

1. Kowal J, Tkach M, Théry C (2014) Biogenesis and secretion of exosomes. Curr Opin Cell Biol 29:116-125. doi:10.1016/j.ceb.2014.05.004, http://dx.doi.org

2. Raposo G, Stoorvogel W (2013) Extracellular vesicles: exosomes, microvesicles, and friends. J Cell Biol 200(4):373-383 . doi:10.1083/ jcb. 201211138

3. Montecalvo A, Larregina AT, Shufesky WJ et al (2012) Mechanism of transfer of functional microRNAs between mouse dendritic cells via exosomes. Blood 119(3):756-766. doi:10.1182/blood-2011-02-338004

4. Lai CP, Kim EY, Badr CE et al. (2015) Visualization and tracking of tumour extracellular vesicle delivery and RNA translation using multiplexed reporters. Nat Commun 6. doi:10.1038/ncomms8029

5. Valadi H, Ekstrom K, Bossios A et al (2007) Exosome-mediated transfer of mRNAs and microRNAs is a novel mechanism of genetic exchange between cells. Nat Cell Biol 9(6):654-659. doi:10.1038/ncbl596

6. Silva J, Garcia V, Zaballos A et al (2011) Vesicle-related microRNAs in plasma of nonsmall cell lung cancer patients and correlation with survival. Eur Respir J 37(3):617-623. doi:10.1183/09031936.00029610

7. Zhang L, Zhang S, Yao J et al (2015) Microenvironment-induced PTEN loss by exosomal microRNA primes brain metastasis outgrowth. Nature 527(7576):100-104. doi:10.1038/naturel5376, http://www.nature. com/nature/journal/v527/n7576/abs/ nature 15376.html\#supplementary-information
8. O'Brien $\mathrm{K}$, Lowry MC, Corcoran $\mathrm{C}$ et al (2015) miR-134 in extracellular vesicles reduces triple-negative breast cancer aggression and increases drug sensitivity., Oncotarget

9. Vaksman O, Trope C, Davidson B et al (2014) Exosome-derived miRNAs and ovarian carcinoma progression. Carcinogenesis 35(9):21132120. doi:10.1093/carcin/bgul30

10. Taylor DD, Gercel-Taylor C (2008) MicroRNA signatures of tumor-derived exosomes as diagnostic biomarkers of ovarian cancer. Gynecol Oncol 110(1):13-21. doi:10.1016/j.ygyno.2008.04.033

11. Corcoran C, Rani S, O'Driscoll L (2014) miR$34 \mathrm{a}$ is an intracellular and exosomal predictive biomarker for response to docetaxel with clinical relevance to prostate cancer progression. Prostate 74(13):1320-1334. doi:10.1002/ pros. 22848

12. Lötvall J, Hill AF, Hochberg F et al (2014) Minimal experimental requirements for definition of extracellular vesicles and their functions: a position statement from the international society for extracellular vesicles. J Extracell Vesicles 3:26913

13. Rani S, O'Brien K, Kelleher FC et al (2011) Isolation of exosomes for subsequent mRNA, MicroRNA, and protein profiling. Methods Mol Biol 784:181-195. doi:10.1007/ 978-1-61779-289-2_13

14. Lässer C, Eldh M, Lötvall J (2012) Isolation and characterization of RNA-containing exosomes. J Vis $\operatorname{Exp}$ 59:3037. doi:10.3791/ 3037 